\title{
Clinical features and treatment results in children with hemangioma
}

\author{
Erman Ataş ${ }^{1}$, Ozan Koç ${ }^{2}$, Hatice A. Artık ${ }^{3}$ \\ ${ }^{1}$ Department of Pediatric Oncology, ${ }^{2}$ Department of Pediatrics, Universitiy of Health Sciences, Gülhane Training and \\ Research Hospital, Pediatrics, Ankara, Turkey; ${ }^{3}$ Department of Dermatology, University of Health Sciences, Dişkapı \\ Yıldırım Beyazıt Training and Desearch Hospital, Ankara, Turkey. E-mail: eatasdr@gmail.com \\ Received: 13th January 2017, Revised: 6th March 2017, Accepted: 6th March 2017
}

SUMMARY: Ataş E, Koç O, Artık HA. Clinical features and treatment results in children with hemangioma. Turk J Pediatr 2017; 59: 254-260.

Hemangioma is a frequent disease which has a proliferative and involution phase. In this single center retrospective study, we evaluated clinical and therapeutic features of hemangiomas in children (n: 49). The median (range) age at onset and at admission were 21 days (10 days-156 months) and 7 months (0.25-192 months), respectively. The localization of lesions was: head region (n: $28 ; 57.2 \%$ ), trunk (n: $8 ; 16.3 \%$ ) trunk, limb (n: $8 ; 16.3 \%$ ), and neck region (n: $5 ; 10.2 \%$ ) neck region. Seventeen patients $(34.7 \%)$ were treated. Following treatments were used: propranolol alone in $12(24.5 \%)$ patients, steroid alone in $2(4.1 \%)$ patients, prednisone plus propranolol in $2(4.1 \%)$ patients, and propranolol plus surgery in $1(2.0 \%)$ patient. The number of hemangioma $(n>1)(p=0.026$, OR $=9.5,95 \% \mathrm{CI} 1.3-69.2)$ and treatment other than observation $(\mathrm{p}=0.008$, OR $=10.5,95 \% \mathrm{CI} 1.8-59.1)$ were significant predictors in the univariate analysis; treatment other than observation was an independent predictor for clinical response $(p=0.014$, $\mathrm{OR}=9.8,95 \% \mathrm{CI}$ 1.5-90.9).

Key words: children, clinical features, hemangioma, outcome, treatment.

Vascular lesions are divided into two main groups: tumors and vascular malformations ${ }^{1}$. Hemangiomas are the most common vascular endothelial benign tumors of childhood ${ }^{2}$. They are usually not obvious at birth. The prevalence in 1-year-old infants is around 10$12 \%^{3}$, and is directly proportional to the age of the application, the size, the visibility and the symptom of the lesion 4 . They are mostly localized on head and neck region ${ }^{5}$.

Rapid growth after birth, stagnation in growth, shrinkage and getting smaller spontaneously are their common clinical course ${ }^{6}$. Superficial endothelial angioblast proliferation responsible for vasculogenesis in proliferative events has been demonstrated 7,8 . As a result, the imbalance between positive and negative vasculogenic factors is influential in the pathogenesis of hemangioma ${ }^{9}$. Tumors show a rapid growth in the 6-10-month period, and become the largest state around 1-year-old-age. After one year of age, especially after 18 months of age, they tend to shrink due to apoptosis rather than proliferation. Apoptosis is highest among 13-48 months and decreases after 48 months ${ }^{10,11}$. In contrast, vascular malformations usually do not get smaller. Female predominance, association with low gestational age and prematurity are other clinical features. ${ }^{12,13}$ Increase in size is the major cause of admission.

Although they are usually followed up without treatment, some hemangiomas - owing to size -may require treatment due to impaired vital organ function, hemorrhage and heart failure. Periorbital, ear canal, nasopharynx, subglottic region are critical localizations of them, and some of them have to take treatment. In this article, clinical and therapeutic features of hemangiomas in children were evaluated.

\section{Material and Methods}

This is a single center, retrospective study. Files of 49 patients with hemangioma who were referred to Department of Pediatric Oncology were evaluated. Ethics Committee approval was obtained from Gülhane Military Medical Academy Local Ethics Committee (03.02.2015- 
7). SPSS 15.0 was used in the analysis of the data. The median, mean, minimum and maximum for continuous variables, percent and number values for discrete variables, and Spearman or Pearson test for correlation were used. Age, sex, place of residence, number of hemangiomas, treatment modality, age of application, presence of birth, and laterality (right-left-midline) for assessment of treatment response were evaluated as possible predictors. Treatment indications for hemangioma were compression to vital organs, cosmetic reasons, complications of critical organ localization such as periorbital, ear canal, nasopharynx, and subglottic region, Kasabach-Meritt syndrome, ulceration and bleeding of hemangioma, and giant hemangioma of liver because of heart failure. Response criteria to treatment were the followings: 1) stop growing, 2) shrinkage or flattening of the lesion, 3) fading of surface color. It was accepted that the lesion in which both of the three criteria were observed had good response, partial response in the lesion in which one of the three criteria was observed, and lack of response in lesions where there was no improvement. Parameters identified with univariate logistic regression analysis was further entered into multivariate analysis, with backward selection, to determine independent predictors of survival. A 5\% type-I error level was used to infer statistical significant.

\section{Results}

The demographic features of 49 children with hemangiomas were summarized in Table I. Growth $(100 \%)$ and bleeding $(8.1 \%)$ of hemangioma were the main clinical problem to apply to hospital. The largest hemangioma was $60 \times 75 \mathrm{~mm}$ with Kasabach-Meritt syndrome, which was the most dangerous complication. There were $5(10.2 \%)$ hemangiomas related to the eye as a specific site. Median (range) values of white blood cell, hemoglobin, platelets, activated partial thromboplastin time (aPTT), prothrombin time (PT), international normalized ratio (INR) were $9.9 \times 10^{3} / \mathrm{mm}^{3}$ (1.6-16.5), $11.7 \mathrm{~g} / \mathrm{L}(9.4-17.4), 340 \times 10^{3} /$ $\mathrm{mm}^{3}$ (61-827), $29.6 \mathrm{sec}(20.7-40.5), 11.6$ $\sec (10.5-16.8)$, and 1 (0.7-1.2), respectively; D-dimer level in a patient with KasabachMeritt syndrome was $>5000 \mathrm{ng} / \mathrm{ml}$ (0-175). Abdominal ultrasonography was performed in 34 patients, and it revealed a hepatic hemangioma in 1 case $(3 \%)$. Computerized tomography (CT) and MRI were used in 2 $(4.1 \%)$ cases with respiratory distress (one with Kasabach-Meritt syndrome); hemangiomas were detected in the glottic area.

Spontaneous regression was observed in $65 \%$ of our cases and the median time of onset of regression was 19 months. Lip hemangiomas in 2 cases of our series did not show regression. There were five periorbital cases. Four of these were treated. Very good response to propranolol treatment was observed. Intralesional steroids were not administered.

In the patient with Kasabach-Meritt, hemangioma did not respond to treatment with methylprednisolone, vincristine, interferonalpha and propranolol, the coagulation parameters could be corrected by embolization. The coagulation parameters quickly improved and no additional transfusions were required. No progression was detected and no additional drug was used. The patient was followed up to one year of age and the lesion was evaluated as $7 \mathrm{~mm}$ in USG.

Only one patient received surgical treatment. There was a strong negative $(r=-0.913, p$ $<0.001)$ correlation between presence of lesion at birth and age of admission, and moderate negative $(\mathrm{r}=-0.37, \mathrm{p}=0.013)$ correlation between gender and size of lesion. In univariate analysis, the number of hemangiomas more than 1 $(p=0.026$, OR $=9.5,95 \%$ CI 1.3-69.2) and undergone to other treatment modalities other than observation $(\mathrm{p}=0.008, \mathrm{OR}=10.5,95 \% \mathrm{CI}$ 1.8-59.1) were found to be possible predictors for the clinical response of hemangioma. In the multivariate analysis, treatment other than observation was an independent predictor of clinical response $(\mathrm{p}=0.014, \mathrm{OR}=9.8,95 \% \mathrm{CI}$ 1.5-90.9) (Table II).

\section{Discussion}

Rate of hemangiomas in terms ranges from 1 to $4 \%$, but this rate increase to $22 \%$ in preterms ${ }^{13}$. Prematurity rate was $6.1 \%$ in this study. In general, $20 \%$ of the cases have lesions at birth; this rate was $59.2 \%$ in our series.

Median admission time of cases was 7 months, and was consistent with a proliferative phase of hemangioma. To be so small to be noticed at birth, late recognition by family, and 
Table I. Clinical Features of Hemangiomas.

\begin{tabular}{|c|c|}
\hline Features & Results \\
\hline Gender: male / female, n (\%) & $21(42.9) / 28(57.1)$ \\
\hline Presence of lesion at birth, n (\%) & $29(59.2)$ \\
\hline Prematurity, n (\%) & $3(6.1)$ \\
\hline Number of lesion:1-2-3-4, n (\%) & $44(89.8)-2(4.1)-2(4.1)-1(2.0)$ \\
\hline Laterality: right / left, n (\%) & $24(49.0) / 25(51.0)$ \\
\hline Age of onset, median (range) & 21 days (10 days-156 mo.) \\
\hline Age of admission (mo.), median (range) & $7(0.25-192)$ \\
\hline Number of lesion, median (range) & $1(1-4)$ \\
\hline Width (mm), median (range) & $20(5-75)$ \\
\hline Height (mm), median (range) & $15(4-60)$ \\
\hline Width $\mathrm{x}$ height $\left(\mathrm{cm}^{2}\right)$, median (range) & $3(0.25-42)$ \\
\hline Male - Female, median (range) & $3(0.25-24)-5(0.35-42)$ \\
\hline \multicolumn{2}{|l|}{ Localization } \\
\hline \multicolumn{2}{|l|}{ Head } \\
\hline Intracranial, n (\%) & $1(2.0)$ \\
\hline Scalp - forehead, n (\%) & $10(20.4)-1(2.0)$ \\
\hline Ear, n (\%) & $2(4.1)$ \\
\hline Cheek - chin, n (\%) & $5(10.2)-1(2.0)$ \\
\hline Eyelid - orbita, n (\%) & $4(8.2)-1(2.0)$ \\
\hline Lip - tongue, n (\%) & $2(4.1)-1(2.0)$ \\
\hline \multicolumn{2}{|l|}{ Neck region } \\
\hline Neck - subglottic - nape, n (\%) & $2(4.1)-2(4.1)-1(2.0)$ \\
\hline \multicolumn{2}{|l|}{ Trunk } \\
\hline Chest -back- liver, n (\%) & $4(8.2)-3(6.2)-1(2.0)$ \\
\hline \multicolumn{2}{|l|}{ Extremities } \\
\hline Shoulder - arm - hand, n (\%) & $1(2.0)-2(4.1)-1(2.0)$ \\
\hline Leg - foot, n (\%) & $3(6.2)-1(2.0)$ \\
\hline Spontaneous regression, $\mathrm{n}(\%)$ & $32(65.3)$ \\
\hline Age of regression onset (mo.), median (range) & $19(18-23)$ \\
\hline Bleeding* (ulceration), n (\%) & $4(8.1)$ \\
\hline Treatment, n (\%) & $17(34.7)$ \\
\hline \multicolumn{2}{|l|}{ Treatment modalities } \\
\hline Propranolol alone, n (\%) & $(24.6)$ \\
\hline Steroid alone, n (\%) & $(4.1)$ \\
\hline Steroid + propranolol, n (\%) & $1(2.0)$ \\
\hline Surgery + propranolol, n (\%) & $1(2.0)$ \\
\hline $\begin{array}{l}\text { Steroid }+ \text { propranolol }+ \text { interpheron alfa }+ \\
\text { vincristine }+ \text { embolization, n }(\%)\end{array}$ & $1(2.0)$ \\
\hline \multicolumn{2}{|l|}{ Treatment localization } \\
\hline Intracranial, n (\%) & $1(2.0)$ \\
\hline Scalp, n (\%) & $3(6.2)$ \\
\hline Cheek, n (\%) & $2(4.1)$ \\
\hline Eyelid - orbita, n (\%) & $3(6.2)-1(2.0)$ \\
\hline Lip - tongue - subglottic, n (\%) & $2(4.1)-1(2.0)-2(4.1)$ \\
\hline Shoulder, n (\%) & $1(2.0)$ \\
\hline Foot, n (\%) & $1(2.0)$ \\
\hline Response, $\mathrm{n} / \mathrm{n}$ total $(\%)$ & $10 / 17(58.8)$ \\
\hline
\end{tabular}

*: scalp (n:3), foot (n: 1) 
interpretation as a birthmark or concerns about the growing of these lesions may be effective at the time of the admission. Our cases were brought with growth and bleeding of hemangioma. Female patients had greater lesions than males; this may be related to the effects of maternal hormones and hormonal changes in the event.

Parallel to the fact that only the hemangiomas adjacent to the lips do not usually regress because of being fed directly from the labial artery, lip hemangiomas in 2 cases of our series did not show regression ${ }^{13}$.

Fifty to $60 \%$ of hemangiomas are localized to the head and neck region, while $25 \%$ are located in the body and $15 \%$ in the extremities ${ }^{5}$. Sen et al. ${ }^{14}$ reported localization of hemangioma as $70 \%$ on the head and neck region in their study. In our cases, hemangiomas were $67.4 \%$ in the head and neck region, $16.3 \%$ in the trunk and $16.3 \%$ in the extremity region, and these were consistent with the literature.

As the lesion size increases, the complication rate increases 11 times; hemorrhage, ulceration, infection and compression findings are some of these complications, the most common complication is ulcerations ${ }^{10}$.

One of the regions where lesion size is important is periorbital hemangiomas ${ }^{15,16}$. Periorbital hemangiomas can cause permanent blindness by compressing the eyeball within as short as 2 weeks ${ }^{15,16}$. Therefore, lesion size in the hemangiomas of periorbital region has a special precaution. Orbital hemangiomas are classified as $<1 \mathrm{~cm}$ in Group 1, $>1$ $\mathrm{cm}$ in Group 2, and unmeasured diffuse eyelid hemangiomas in Group 3. Group 4 is defined for patients with PHACE (posterior fossa malformations, hemangiomas, arterial anomalies, aortic coarctation, cardiac anomalies, midline developmental disorders and congenital cataracts, microphthalmia, optic nerve hypoplasia) ${ }^{17}$.

Hemangiomas usually do not require treatment, but compression to vital organs, cosmetic reasons and complications may require treatment. The cases of hemangiomatosis may require further examination in terms of visceral organ involvement ${ }^{18}$. Having $\geq 5$ hemangiomas is called hemangiomatosis, and the condition to be noted in these patients is the more visceral organ involvement than the classical hemangioma patients. Since it is the most commonly involved intraabdominal organ, abdominal ultrasonography (USG) should be planned to assess liver involvement ${ }^{18}$. These organ involvements can lead to lifethreatening complications, especially in the first months of life, and have prognostic significance in terms of treatment approach ${ }^{18}$. Hemangiomas were detected only in 1 (3\%) of the 34 patients who had undergone abdominal USG abdominal incidentally, in which case there was no cutaneous hemangioma. When we reviewed the literature, this ratio varied between $10-22 \% 18,19$.

Kasabach-Meritt syndrome accompanied by thrombocytopenia, hemolytic anemia and consumption coagulopathy was defined in capillary hemangiomas in 1940. This consumption coagulopathy is due to endothelial dysfunction in the hemangioma ${ }^{20}$. We had first planned to start propranolol for the patient Kasabach-Meritt syndrome, but due to progressive clinic, methylprednisolone, vincristine, interferon-alpha therapies which has been successfully used in Kasabach-Meritt treatment ${ }^{21}$, were decided to start. Intra-arterial embolization was performed because of the

Table II. Effects of Some Predictors on Clinical Response of Hemangioma.

\begin{tabular}{|c|c|c|c|c|c|}
\hline \multirow[b]{2}{*}{ Predictor } & \multirow[b]{2}{*}{ Category } & \multicolumn{2}{|c|}{ Univariate analysis } & \multicolumn{2}{|c|}{ Multivariate analysis } \\
\hline & & OR $(95 \% \mathrm{CI})$ & $\mathrm{p}$ & OR $(95 \% \mathrm{CI})$ & $\mathrm{p}$ \\
\hline $\begin{array}{l}\text { Number of } \\
\text { hemangioma (n) }\end{array}$ & "n $>1$ " versus " $\mathrm{n}=1$ " & $9.5(1.3-69.2)$ & 0.026 & & \\
\hline Treatment modalities & $\begin{array}{l}\text { "Other treatment } \\
\text { modalities" versus } \\
\text { "Observation alone" }\end{array}$ & $10.5(1.8-59.1)$ & 0.008 & $9.8(1.5-90.9)$ & 0.014 \\
\hline
\end{tabular}

CI: confidence intervals; OR: Odds ratio was estimated using logistic regression model. Simple: first was selected to evaluate the effect of categorical predictors. 
lack of adequate and rapid response to these treatments and the high risk of bleeding. In this patient, propranolol therapy could be started alone or in addition to this treatment ${ }^{22}$.

In the diagnosis of hemangiomas, USG, MRI, endoscopic imaging methods and computed tomography can be used. Abdominal USG was used to scan the liver hemangioma. Tomography and MRI were usually not used. After oral propranolol was started, the complaints decreased. Deep resident hemangioma with cutaneous presentation could only be detected by MRI after USG.

Hemangiomas with critical organ localization may require treatment, because they will lead to complications. Periorbital in terms of visual impairment, ear canal in terms of hearing, nasopharynx, and subglottic region in terms of respiratory distress are these critical localizations. Haggstrom et al. ${ }^{10}$ have reported that important criteria for initiation of treatment are size and location of the lesions, especially on face. Treatment modalities for hemangiomas can be roughly divided into two categories, systemic and local. Glucocorticoids and propranolol are the first preferred agents ${ }^{23}, 24$. Oksiuta et al. ${ }^{22}$ reported that oral propranolol therapy showed excellent efficacy in $87 \%$ of patients, and that severe tachycardia was observed in only one patient. They also suggested that the dose of propranolol could be increased to $3 \mathrm{mg} / \mathrm{kg}$ and that topical treatment may be an alternative treatment in cases who oral treatment can not be tolerated ${ }^{22}$. Kovacevic et al. ${ }^{25}$ showed excellent response to topical treatment containing $1 \%$ propranolol in $62.5 \%$ of patients with superficial infantile hemangioma. All patients had regression after lesions after treatment. According to randomized controlled trials and meta-analyses, efficacy was found in the range of $96-98 \%$ at 6 months of use of propranolol at a dose of 2-3 $\mathrm{mg} / \mathrm{kg} /$ day, and severe side effects were found ${ }^{26-29}$. The most common side effects have been reported as bronchitis, sleep disturbances, diarrhea and vomiting at rates of $10 \%$ or more ${ }^{26}$. Vincristine and interferon alpha can be used as second choice in unresponsive cases $^{30,31}$. Topical treatments can be used in small, superficial hemangiomas without life threatening. These treatments consist of agents such as intralesional steroids, topical steroids, imiquimode, and topical timolol ${ }^{32-35}$. Surgery in hemangiomas of periorbital region with cosmetic and organ dysfunction in selected cases, laser in cutaneous hemangiomas with a depth of not less than $1.2 \mathrm{~mm}$, embolization in liver involvement and Kasabach-Meritt syndrome are the other treatment methods that can be applied ${ }^{36-38}$.

Oral propranolol or steroids are the first choice in glottic hemangiomas and laser ablation methods are used in unresponsive cases ${ }^{39,}{ }^{40}$. In cases with unexplained upper respiratory obstruction findings, hemangiomas should be considered in the differential diagnosis. Approximately 35\% of our patients were treated: $64 \%$ of the cases responded to treatment; treatment response rates were compatible with the literature. The efficacy of oral propranolol therapy and oral steroid treatments varies between $60 \%$ and $84 \%^{23,41}$. Only one patient received surgical treatment. Other patients were treated with propranolol and/or oral steroids. The lesions of the treated patients were mostly localized to the head and neck region. Concentration of the lesions of the patients in the head and neck region causes an increase in treatment rates. This can be attributed to the placement of important organs and cosmetics in the head and neck region. Intracranial, shoulder (Kasabach-Meritt), tongue, lip, subglottic, eyelid and orbital were the critical regions where we treated.

In conclusion, hemangiomas grow very rapidly in the first year of life, although they are very small at birth. Ulcers, infections, hemorrhages and special places such as larynxes, tongue, eyelids, ear canal are the treatment indications. Treatment modalities include observation, medical treatment options such as steroid, propranolol, interferon, chemotherapy, interventional radiologic lesion embolization, surgical resection and laser. In our study, the number of hemangiomas and treatment modalities out of observation were found to be effective in the hemangioma course.

\section{REFERENCES}

1. Enjolras O, Mulliken JB. Vascular tumors and vascular malformations (new issues). Adv Dermatol 1997; 13: 375-423.

2. Goelz R, Poets CF. Incidence and treatment of infantile hemangioma in preterm infants. Arch Dis Child Fetal Neonatal Ed 2015; 100: F85-F91. 
3. Jacobs AH, Walton RG. The incidence of birthmarks in the neonate. Pediatrics 1976; 58: 218-222.

4. Alper JC, Holmes LB. The incidence and significance of birthmarks in a cohort of 4,641 newborns. Pediatr Dermatol 1983; 1: 58-68.

5. Finn MC, Glowacki J, Mulliken JB. Congenital vascular lesions: Clinical application of a new classification. J Pediatr Surg 1983; 18: 894-900.

6. Frieden IJ, Haggstrom AN, Drolet BA, et al. Infantile hemangiomas: Current knowledge, future directions. Proceedings of a research workshop on infantile hemangiomas, April 7-9, 2005, Bethesda, Maryland, USA. Pediatr Dermatol 2005; 22: 383-406.

7. Yu Y, Fuhr J, Boye E, et al. Mesenchymal stem cells and adipogenesis in hemangioma involution. Stem Cells 2006; 24: 1605-1612.

8. Nguyen VA, Fürhapter C, Romani N, Weber F, Sepp $\mathrm{N}$. Infantile hemangioma is a proliferation of beta 4-negative endothelial cells adjacent to HLA-DRpositive cells with dendritic cell morphology. Hum Pathol 2004; 35: 739-744.

9. Bielenberg DR, Bucana CD, Sanchez R, Mulliken JB, Folkman J, Fidler IJ. Progressive growth of infantile cutaneous hemangiomas is directly correlated with hyperplasia and angiogenesis of adjacent epidermis and inversely correlated with expression of the endogenous angiogenesis inhibitor, IFN-beta. Int J Oncol 1999; 14: 401-408.

10. Haggstrom AN, Drolet BA, Baselga E, et al. Prospective study of infantile hemangiomas: clinical characteristics predicting complications and treatment. Pediatrics 2006; 118: 882-887.

11. Razon MJ, Kraling BM, Mulliken JB, Bischoff J. Increased apoptosis coincides with onset of involution in infantile hemangioma. Microcirculation 1998; 5: 189-195.

12. Chiller KG, Passaro D, Frieden IJ. Hemangiomas of infancy: Clinical characteristics, morphologic subtypes, and their relationship to race, ethnicity, and sex. Arch Dermatol 2002; 138: 1567-1576.

13. Amir J, Metzker A, Krikler R, Reisner SH. Strawberry hemangioma in preterm infants. Pediatr Dermatol 1986; 3: 331-332.

14. Şen Z, Özakpınar HR, Gökrem S, ve ark. Kutanöz vasküler lezyonlarda klinik yaklaşımlarımız. Ankara Üniversitesi Tip Fakültesi Mecmuası 2002; 55: 193-204.

15. Ceisler EJ, Santos L, Blei F. Periocular hemangiomas: what every physician should know. Pediatr Dermatol 2004; 21: 1-9.

16. Schwartz SR, Blei F, Ceisler E, Steele M, Furlan L, Kodsi S. Risk factors for amblyopia in children with capillary hemangiomas of the eyelids and orbit. J AAPOS 2006; 10: 262-268.

17. Sevinir B. Çocukluk çağında hemanjiyomlar ve klinik özellikleri. Güncel Pediatri 2006; 3: 63-68.

18. Horii KA, Drolet BA, Frieden IJ, et al. Prospective study of the frequency of hepatic hemangiomas in infants with multiple cutaneous infantile hemangiomas. Pediatr Dermatol 2011; 28: 245-253.
19. Canty KM, Horii KA, Ahmad H, Lowe LH, Nopper AJ. Multiple cutaneous and hepatic hemangiomas in infants. South Med J 2014; 107: 159-164.

20. Kasabach HH, Merritt KK. Capillary hemangioma with extensive purpura. Am J Dis Child 1940; 56: 10631070.

21. Yoon HS, Lee JH, Moon HN, Seo JJ, Im HJ, Goo HW. Successful treatment of retroperitoneal infantile hemangioendothelioma with Kasabach-Merritt syndrome using steroid, alpha-interferon, and vincristine. J Pediatr Hematol Oncol 2009; 31: 952-954.

22. Oksiuta M, Matuszczak E, Debek W, DzienisKoronkiewicz E, Hermanowicz A, Tylicka M. Treatment of problematic infantile hemangiomas with propranolol: a series of 40 cases and review of the literature. Postepy Hig Med Dosw (Online) 2014; 68: 1138-1144.

23. Hogeling M, Adams S, Wargon O. A randomized controlled trial of propranolol for infantile hemangiomas. Pediatrics 2011; 128: e259-e266.

24. Edgerton MT. The treatment of hemangiomas: with special reference to the role of steroid therapy. Ann Surg 1976; 183: 517-532.

25. Kovacevic M, Lukinovic Skudar V, Maricic G, KrnjevicPezic G, Stanimirovic A. Topical propranolol cream in treatment of superficial infantile hemangiomas: A literature review and 4 years of clinical experience. Acta Dermatovenerol Alp Pannonica Adriat 2014; 23: 75-78.

26. Hoeger PH, Harper JI, Baselga E, et al. Treatment of infantile hemangiomas: Recommendations of a European expert group. Eur J Pediatr 2015; 174: 855865.

27. Hermans DJ, Bauland CG, Zweegers J, van Beynum IM, van der Vleuten CJ. Propranolol in a case series of 174 patients with complicated infantile haemangioma: Indications, safety and future directions. Br J Dermatol 2013; 168: 837-843.

28. Solman L, Murabit A, Gnarra M, Harper JI, Syed SB, Glover M. Propranolol for infantile haemangiomas: Single centre experience of 250 cases and proposed therapeutic protocol. Arch Dis Child 2014; 99: 11321136.

29. Marqueling AL, Oza V, Frieden IJ, Puttgen KB. Propranolol and infantile hemangiomas four years later: A systematic review. Pediatr Dermatol 2013; 30: 182-191.

30. Perez J, Pardo J, Gomez C. Vincristine--an effective treatment of corticoid-resistant life-threatening infantile hemangiomas. Acta Oncol 2002; 41: 197-199.

31. Ezekowitz RA, Mulliken JB, Folkman J. Interferon alfa-2a therapy for life-threatening hemangiomas of infancy. N Engl J Med 1992; 326: 1456-1463.

32. Chen MT, Yeong EK, Horng SY. Intralesional corticosteroid therapy in proliferating head and neck hemangiomas: a review of 155 cases. J Pediatr Surg 2000; 35: 420-423.

33. Guo S, Ni N. Topical treatment for capillary hemangioma of the eyelid using beta-blocker solution. Arch Ophthalmol 2010; 128: 255-256. 
34. Elsas FJ, Lewis AR. Topical treatment of periocular capillary hemangioma. J Pediatr Ophthalmol Strabismus 1994; 31: 153-156.

35. Sidbury R, Neuschler N, Neuschler E, et al. Topically applied imiquimod inhibits vascular tumor growth in vivo. J Invest Dermatol 2003; 121: 1205-1209.

36. Dinehart SM, Kincannon J, Geronemus R. Hemangiomas: Evaluation and treatment. Dermatol Surg 2001; 27: 475-485.

37. Stier MF, Glick SA, Hirsch RJ. Laser treatment of pediatric vascular lesions: Port wine stains and hemangiomas. J Am Acad Dermatol 2008; 58: 261-285.

38. Enjolras O, Mulliken JB. The current management of vascular birthmarks. Pediatr Dermatol 1993; 10: 311313.
39. Peridis S, Pilgrim G, Athanasopoulos I, Parpounas K. A meta-analysis on the effectiveness of propranolol for the treatment of infantile airway hemangiomas. Int J Pediatr Otorhinolaryngol 2011; 75: 455-460.

40. Rahbar R, Nicollas R, Roger G, et al. The biology, management of subglottic hemangioma: past, present, future. Laryngoscope 2004; 114: 1880-1891.

41. Bennett ML, Fleischer AB, Jr., Chamlin SL, Frieden IJ. Oral corticosteroid use is effective for cutaneous hemangiomas: an evidence-based evaluation. Arch Dermatol 2001; 137: 1208-1213. 